\author{
Professor Sebastian Ion CEPTUREANU, PhD \\ E-mail: sebastian.ceptureanu @man.ase.ro \\ The Bucharest University of Economic Studies \\ Professor Roy CERQUETI, PhD \\ Sapienza University of Rome, Rome, Italy \\ E-mail: roy.cerqueti@uniroma1.it \\ Professor Eduard Gabriel CEPTUREANU, PhD \\ The Bucharest University of Economic Studies \\ E-mail: eduard.ceptureanu@man.ase.ro \\ Professor Gurjeet DHESI, PhD \\ London South Bank University, London, United Kingdom \\ E-mail: dhesig@ lsbu.ac.uk \\ Iuliana LUCHIAN, PhD student \\ E-mail: iulia.luchian@ase.ro \\ The Bucharest University of Economic Studies
}

\title{
DOES DEATH ANXIETY INHIBIT PRODUCT INNOVATION? AN EXPLORATORY STUDY IN SMALL MANUFACTURING COMPANIES
}

\begin{abstract}
The study analyzed the entrepreneurs' choice for explorative and exploitative innovation and their effects on product innovation. Death anxiety, a psychological factor, is analyzed as it is assumed to be important in mediating the relationship between explorative or exploitative innovation and product innovation. A sample of 60 entrepreneurs from small manufacturing companies was analyzed in three waves over three consecutive years, while the data was analyzed using PLS-SEM. Empirical evidence supports the assumption that entrepreneurs' fear of death partially mediates explorative and exploitative innovation influence on product innovation. The findings show that death anxiety is negatively affecting explorative innovation, with negative effects for radical innovation, and positively influencing exploitative innovation, supporting incremental innovation. The effects may be far reaching, only if considering the current SARS-COV-2 epidemics, which may radically change not only the social landscape, but also the way the entrepreneurs are substantiating their decisions.

Keywords: explorative innovation; exploitative innovation; death anxiety; product innovation.
\end{abstract}

JEL Classification:O31, M11, L26, D9

DOI: 10.24818/18423264/55.1.21.09 
Sebastian Ion Ceptureanu, Roy Cerqueti, Eduard Gabriel Ceptureanu, Gurjeet Dhesi, Iuliana Luchian

\section{Introduction}

Product Innovation (PI) is important for business survival and success (Markovic et al., 2020). Due to relatively short product life cycles, PI may prove critical for those firms competing in dynamic environments. Entrepreneurs may embrace PI to improve turnover and profit by targeting more customers or market segments when alternative products are largely available.

We argue that PI is a result of entrepreneur's choice to pursue either Explorative Innovation (EXPLOR) or Exploitative Innovation (EXPLOIT). The analysis of EXPLOR and EXPLOIT has been intensively scrutinized in the literature in the last decade (Birkinshaw \& Gupta, 2013). Previous studies have demonstrated that effective entrepreneurs possess the ability to combine EXPLOR and EXPLOIT, a process known as innovation ambidexterity, achieving improved outcomes. Even though both types of innovation are often considered in the context of innovation ambidexterity (Lee et al., 2017), the present study analyses the entrepreneurs' choice between EXPLOR and EXPLOIT and not their combination.

Research on innovation has increasingly scrutinized factors that explain why entrepreneurs are eager or, on contrary, reluctant to adopt new or improved products. These factors are mostly related to product (Moon et al., 2016), consumers (Heidenreich \& Handrich, 2015), and situation specific (Kim \& Park, 2011).

This paper explains the relationship between PI and EXPLOR and EXPLOIT through psychological factors. The fear of own mortality, or Death Anxiety (DA), describing individual threat of death, may prove critical in entrepreneurs' decision-making processes. However, little is known about the impact of DA on innovation (Boeuf, 2019). This research indicates that DA may hamper innovation related choices of entrepreneurs.

In the literature, a positive effect of DA on PI has been demonstrated (Das et al., 2014). Investigating the impact of DA on entrepreneurs' choice between EXPLOR and EXPLOIT improves the understanding the role of existential threats, represented by DA, on innovation. DA is activated by threats such as terrorism, economic recessions, armed conflicts or epidemic diseases (Boeuf, 2019). By assessing the impact of DA on entrepreneurs' choice for innovation, the paper demonstrates that psychological factors, in this case existential threats, influence entrepreneurs' choices.

Finally, the research findings indicate that the impact of DA on PI is influenced by entrepreneur's choice toward EXPLOR or EXPLOIT. By choosing the less radical type of innovation (EXPLOIT), the perceived risks associated with innovative new or improved products (EXPLOR) reduce the psychological conflict determined by DA.

The paper is organized as follows. In Section 2, a literature review is presented, which lays the foundation for research hypotheses development. Section 3 contains a description of the considered dataset and outlines also the methods 
Does Death Anxiety Inhibit Product Innovation? An Exploratory Study in Small Manufacturing Companies

employed for data analysis. The main empirical findings are outlined in Section 4, while Section 5 provides a discussion of the results, along with their implications for literature; moreover, it offers some conclusive remarks.

\section{Prior studies on measuring regional sustainable development}

\subsection{Explorative and Exploitative Innovation in the context of Product Innovation}

There are various approaches regarding how EXPLOR and EXPLOIT are contributing to PI. One approach, assumed in this study, considers distinct periods of exploration and exploitation, separated in time; a second one proposes a simultaneous pursuit of them, but in distinct organizational units or by outsourcing either one; finally, one last approach assumes a simultaneous pursuit of EXPLOR and EXPLOIT by managing the tension which occurs. This paper perspective is in vein with the first approach, with EXPLOR and EXPLOIT separated in time due to limited amount of available resources in small companies. When an entrepreneur chose EXPLOR, even though it may implement to some extent EXPLOIT, we assumed to be marginal, and vice versa. The pursuit of solely EXPLOR assumes that the entrepreneur use all the resources and capabilities, including those which initially were assigned for EXPLOIT (Piao \& Zajac, 2016).

By integrating different resources, EXPLOR and EXPLOIT entail two distinct innovation approaches (Wei et al., 2014). EXPLOR focuses on new product development and exploration of innovation related opportunities, increasing the likelihood of developing new and innovative products whereas EXPLOIT focuses on refining execution and efficiency of the existing products (He \& Wong, 2004) and providing the resources needed (Cao et al., 2009).

EXPLOR put value on the generation of new products (Rothaermel \& Alexandre, 2009). As a choice, it is preferred by those entrepreneurs making use of their companies' disruptive capabilities to create new products (Lin et al., 2017). Implementing EXPLOR often takes more time than implementing EXPLOIT, with higher associated risks and costs. Therefore, this long-term orientation determines less favorable operational performance, making over-engagement in EXPLOIT potentially harmful for small firms in terms of PI (Prange \& Verdier, 2011).

Entrepreneurs engaging in EXPLOIT are capitalizing on existing resources, knowledge and assets to innovate. As such, they emphasize past innovation replication and improving innovation competences, focusing on the development of existing products (Lin et al., 2017). As a result, the products will be more durable or feature new functionalities. With EXPLOIT less prone to the uncertainties compared to EXPLOR (Prange \& Verdier, 2011), it allows experience accumulation, facilitating production costs cuts. However, focusing on EXPLOIT makes the entrepreneurs less sensitive to technological changes. Over-engagement in EXPLOIT decreases the variety in product range, which is detrimental to PI. Therefore, we hypothesize that:

\section{DOI: 10.24818/18423264/55.1.21.09}


Sebastian Ion Ceptureanu, Roy Cerqueti, Eduard Gabriel Ceptureanu, Gurjeet Dhesi, Iuliana Luchian

H1: Entrepreneurs choice toward EXPLOR is positively correlated with PI.

$\mathrm{H} 2$ : Entrepreneurs choice toward EXPLOIT is positively correlated with PI.

\subsection{Death Anxiety and Product Innovation}

A large part of the literature on innovation assumes that entrepreneurs have a propensity to innovate because all innovations are supposedly good (Talke \& Heidenreich, 2014). Various studies have identified different factors explaining why new or improved innovative products are adopted, such as originality, performance, costs and product information (Moon et al., 2016).

The entrepreneur, as any other individual, feels threatened and may seek to counteract DA through self-protection mechanisms that offer a sense of security (Sedikides \& Wildschut, 2018). Innovation may cause a conflict with entrepreneur's individual predispositions, leading to inhibition or even resistance to innovation. Similarly, entrepreneurs are reluctant to innovation when it requires too much change in their established behavioral habits or patterns or when it does not fit their social or personal values (Kim \& Park, 2011). The psychology literature suggests that DA triggers a psychological discomfort among individuals that results from self-preservation and the awareness of inevitable mortality (Boeuf, 2019), activating reactions focused on coping with the tension and reducing their discomfort. As DA may change entrepreneurs' sense of meaning in life, they may counter it by initiating defensive actions offering a sense of security (Das et al., 2014); in this case, they may become inhibited in choosing EXPLORE over EXPLOIT. To reassure their values against DA, entrepreneurs turn to a protective perception of reality (Routledge et al., 2011), making them to increases efforts to achieve meaning and provides a sense of life. New or improved innovative products are associated with uncertainty and risk and the choice toward EXPLOR may imply a potential conflict with the entrepreneur's values and patterns.

New or improved innovative products adoption depends on the compatibility between innovation and entrepreneurs' values (Kim \& Park, 2011). It is hindered when entrepreneurs have difficulties in mentally projecting new uses of the new or improved innovative products (Zhao et al., 2012). The entrepreneurs may reject EXPLOR to prevent the psychological conflict generated by the uncertainties associated with the novelty of the products or technology. To cope with DA, entrepreneurs usually choose EXPLOIT over EXPLOR, therefore rejecting new or improved innovative product adoption.

The impact of DA on PI adoption is influenced by the entrepreneur's tendency to choose new behaviors. Entrepreneur's propensity toward new innovative products is one of the key drivers of innovation adoption, with highly innovative entrepreneurs favoring new products to a greater extent. Entrepreneurs choosing EXPLOR present a higher level of risk tolerance while those choosing EXPLOIT are more likely to engage in risk-reduction actions toward innovation. Therefore, we hypothesize that:

DOI: $10.24818 / 18423264 / 55.1 .21 .09$ 
Does Death Anxiety Inhibit Product Innovation? An Exploratory Study in Small Manufacturing Companies

H3a. DA mediates the relationship between entrepreneur's choice toward EXPLOR and PI.

H3b. DA mediates the relationship between entrepreneur's choice toward EXPLOIT and PI.

The conceptual model is presented below:

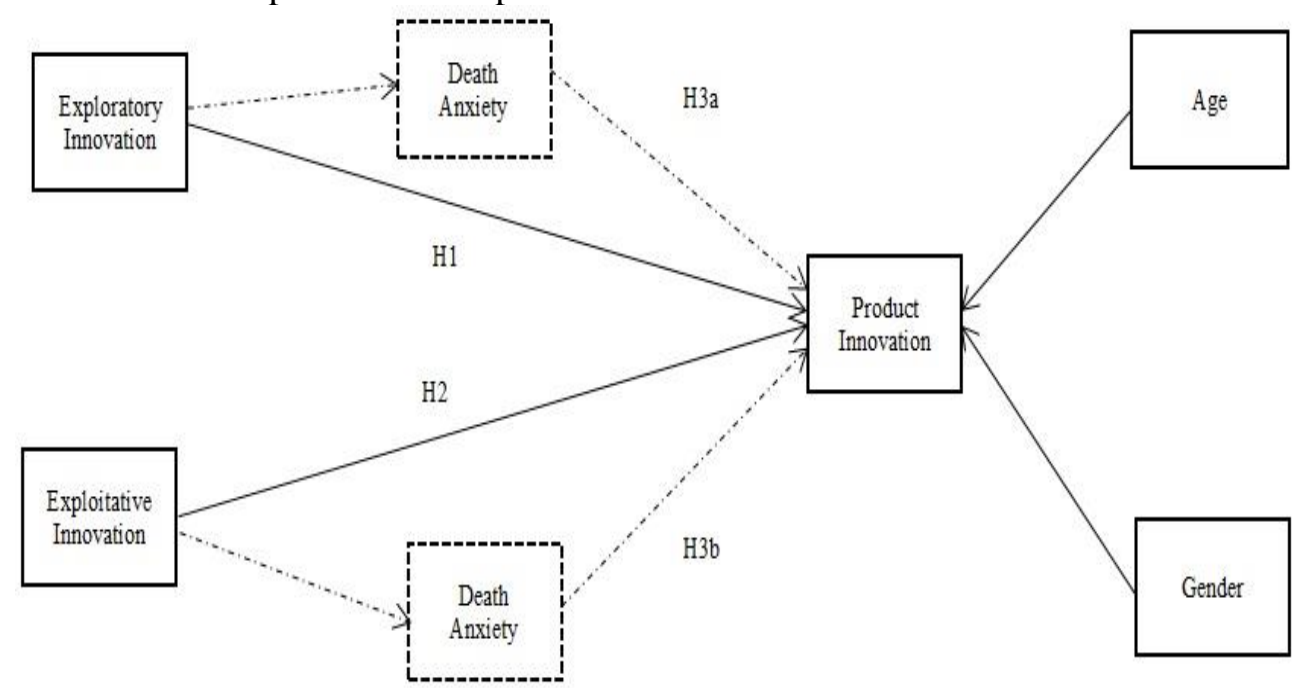

Figure 1.Conceptual model

\section{Research methodology}

\subsection{Sample and data collection}

This study was performed on a convenience sample of 60 Romanian entrepreneurs from small sized manufacturing companies in Bucharest-Ilfov development region. The region is the most developed administrative region of Romania and comprises Bucharest, the capital city. The choice to select small sized companies rests in the fact that the authors wanted that the decisions in the company, and especially those regarding innovation, to lay entirely with the entrepreneurs. At the same time, manufacturing small companies usually lack resources to simultaneously pursue both EXPLOR and EXPLOIT, making easy to determine the choice of the entrepreneurs for one of them. If they would have implemented them simultaneously, their combined effect (innovation ambidexterity) would have been much more difficult to assess.

To test the research hypotheses, the authors have conceptualized a questionnaire composed of five parts: the first one presents the aims and scopes of the research; the second one collects the data on the control variables; the third part consists of EXPLOR and EXPLOIT items; the fourth part consists of DA items; the fifth part consists of PI items. An early draft was discussed with 15 scholars and entrepreneurs. An improved version, based on their recommendations, was

DOI: $10.24818 / 18423264 / 55.1 .21 .09$ 
Sebastian Ion Ceptureanu, Roy Cerqueti, Eduard Gabriel Ceptureanu, Gurjeet Dhesi, Iuliana Luchian

used to carry out a pilot test in which interviews were conducted with 30 entrepreneurs, allowing a final calibration for the definitive version of the questionnaire.

The questionnaires were sent to the same 60 selected entrepreneurs each year for the last three years (2018-2020), by email, and collected each year over a period of 3 months, from February to April except 2020 when, due to COVID-19 outbreak, were collected from February to June. In the end, 174 valid questionnaires were collected and analyzed, with several invalided each year ( 2 in 2018, 1 in 2019, 3 in 2020) due to inconsistencies and, in two cases, bankruptcy. The authors ensured anonymity and confidentiality of the participants. The data were analyzed by means of the partial least squares-structural equation modeling (PLS-SEM) supported by SmartPLS software.

\subsection{Measurement}

Dependent variable: PI construct (4 items) was adapted from Wang \& Ahmed (2004), and Zhang \& Li (2010) studies. It refers to two types of products: new products and improved products. Newness is a concept understood differently in the literature. Because the literature provides different definitions for what new and improved products, for this study, new products were represented by those products new for the company, incorporating new technology. Improved products represent developments of existing products, therefore not new for the company, but incorporating new technology for the company. However, contrary to some scholars (Boeuf, 2019), the authors do not consider PI as representing those products changing the consumers' patterns, therefore more closely related to disruptive innovation. A five-point Likert scale to measure the importance of each item was used, with respondents asked to assess PI in comparison with their main competitor(s) in the industry in the last three years and considered the average of the scores for the four items.

Independent variables: Both EXPLOR (4 items) and EXPLOIT (4 items) constructs were adapted from He \& Wong (2004) and Cao et al. (2009). A fivepoint Likert scale to measure the importance of each item compared with their competitors in the industry.

Mediating variable: DA construct (12 items) was measured by using Existential Death Anxiety Scale (EDAS) (Jong \& Halberstadt, 2019).

Control variables: The study controlled two variables, entrepreneur's age (AGE) and gender (GENDER). Age and gender were used as control variables in several previous studies focused on DA (Chuin \& Choo, 2009; Cai et al., 2017). 
Does Death Anxiety Inhibit Product Innovation? An Exploratory Study in Small Manufacturing Companies

\begin{tabular}{|c|c|c|c|c|}
\hline \multicolumn{5}{|c|}{$\begin{array}{l}\text { Table1. Measurement model evaluation: variables and items, along with } \\
\text { loadings, construct reliability (CR) and average variance extracted (AVE) }\end{array}$} \\
\hline Construct & Items & Loadings & CR & AVE \\
\hline \multirow{4}{*}{ EXPLOR } & $\begin{array}{l}\text { I assign important resources to introduce new, } \\
\text { innovative generations of products }\end{array}$ & 0.732 & \multirow[t]{4}{*}{0.822} & \multirow[t]{4}{*}{0.553} \\
\hline & $\begin{array}{l}\text { I assign important resources to introduce new } \\
\text { ranges of innovative products }\end{array}$ & 0.751 & & \\
\hline & $\begin{array}{l}\text { I assign important resources to access new } \\
\text { markets }\end{array}$ & 0.713 & & \\
\hline & $\begin{array}{l}\text { I assign important resources to incorporate new } \\
\text { technology in the new products }\end{array}$ & 0.761 & & \\
\hline \multirow{4}{*}{ EXPLOIT } & $\begin{array}{l}\text { I assign important resources to improve the } \\
\text { quality of existing products by using new } \\
\text { technology }\end{array}$ & 0.751 & \multirow[t]{4}{*}{0.837} & \multirow[t]{4}{*}{0.544} \\
\hline & $\begin{array}{l}\text { I assign important resources to improve } \\
\text { production flexibility by using new technology }\end{array}$ & 0.773 & & \\
\hline & $\begin{array}{l}\text { I assign important resources to reduce production } \\
\text { costs by using new technology }\end{array}$ & 0.742 & & \\
\hline & $\begin{array}{l}\text { I assign important resources to reduce material } \\
\text { consumption by using new technology }\end{array}$ & 0.796 & & \\
\hline \multirow{12}{*}{ DA } & The thought of my own death frightens me & 0.755 & \multirow[t]{12}{*}{0.852} & \multirow[t]{12}{*}{0.509} \\
\hline & $\begin{array}{l}\text { I am troubled by the fact that someday I will no } \\
\text { longer be alive }\end{array}$ & 0.745 & & \\
\hline & The finality of death is frightening to me & 0.716 & & \\
\hline & My mortality troubles me & 0.702 & & \\
\hline & Thinking about being dead fills me with dread & 0.724 & & \\
\hline & $\begin{array}{l}\text { It upsets me to think that someday I will no } \\
\text { longer be in this world }\end{array}$ & 0.729 & & \\
\hline & $\begin{array}{l}\text { The idea of never experiencing the world again } \\
\text { after I die frightens me }\end{array}$ & 0.752 & & \\
\hline & I am scared that death will be the end of me & 0.709 & & \\
\hline & The loss of my consciousness in death scares me & 0.759 & & \\
\hline & I am scared that death will be the end of my self & 0.738 & & \\
\hline & $\begin{array}{l}\text { I am scared that death will extinguish me as a } \\
\text { person }\end{array}$ & 0.761 & & \\
\hline & $\begin{array}{l}\text { Never feeling anything again after I die upsets } \\
\text { me }\end{array}$ & 0.729 & & \\
\hline \multirow[t]{4}{*}{ PI } & $\begin{array}{l}\text { Ratio of new products to total number of } \\
\text { products }\end{array}$ & 0.737 & \multirow[t]{4}{*}{0.854} & \multirow[t]{4}{*}{0.572} \\
\hline & Ratio of new products sales to total sales & 0.782 & & \\
\hline & $\begin{array}{l}\text { Ratio of improved products to total number of } \\
\text { products }\end{array}$ & 0.808 & & \\
\hline & Ratio of improved products sales to total sales & 0.823 & & \\
\hline
\end{tabular}

DOI: $10.24818 / 18423264 / 55.1 .21 .09$ 
Sebastian Ion Ceptureanu, Roy Cerqueti, Eduard Gabriel Ceptureanu, Gurjeet Dhesi, Iuliana Luchian

The regression model for the analysis is then:

$\mathrm{PI}=\alpha+\beta 1 \mathrm{EXPLOR}+\beta 2$ EXPLOIT $+\beta 3 \mathrm{DA}+\beta 4 \mathrm{AGE}+\beta 5 \mathrm{GENDER}+\varepsilon$,

where $\alpha, \beta 1, \beta 2, \beta 3, \beta 4, \beta 5$ are the parameters to be calibrated; $\varepsilon$ is an error term.

\subsection{Measurement model}

The measurement model consists of individual item reliability, internal consistency and discriminant validity.

Individual item reliability supposed examination of the loadings of the measures with their respective construct, with a minimum threshold of 0.70 (Hair et al., 2006). In Table 1 all factor loadings are higher than the established threshold.

Internal consistency required analysis of construct reliability and convergent validity. In order to interpret construct reliability, Hair et al. (2006) suggest a threshold of at least 0.7. All of the constructs are proved to be reliable, with all measures of $\mathrm{CR}$ above 0.8 . To test convergent validity, the authors used the average variance extracted (AVE). According to Hair et al. (2006) its minimum threshold is 0.5 . This condition is fulfilled by all constructs.

Discriminant validity refers to the extent to which one construct differs from others. To assess it, the square root of AVE is used. AVE for one construct should be greater than its correlation coefficient with any other construct i.e., the squared correlation between two constructs. This condition is fulfilled for all the variables (see Table 2). The correlation coefficients of constructs are below the square root of AVE, proving that each of them has good discriminant validity.

Table2. Correlation of constructs

\begin{tabular}{|l|l|l|l|l|l|l|}
\hline & Mean & Std. dev. & \multicolumn{1}{|c|}{$\mathbf{1}$} & $\mathbf{2}$ & $\mathbf{3}$ & $\mathbf{4}$ \\
\hline 1 EXPLOR & 2.614 & 1.108 & 0.743 & & & \\
\hline 2 EXPLOIT & 2.856 & 1.059 & 0.028 & 0.757 & & \\
\hline 3 DA & 2.108 & 1.022 & $-0.249^{* *}$ & 0.081 & $0.726^{* *}$ & \\
\hline 4 PI & 2.029 & 1.442 & $0.240^{* *}$ & 0.112 & 0.074 & 0.735 \\
\hline
\end{tabular}

To check multicollinearity, the variance inflation factor (VIF) was used (Diamantopoulos \& Winklhofer, 2001). The VIF of EXPLOR and EXPLOIT were the common threshold value of 5 established by Mason \& Perreault (1991), proving minimal collinearity.

\subsection{Structural model}

For the structural model, the variance explained $\left(R^{2}\right)$ in the dependent constructs and the path coefficients $(\beta)$ are assessed, with the aim of indicating the relative strength of the relationships between constructs (see Figure 2). 
Does Death Anxiety Inhibit Product Innovation? An Exploratory Study in Small Manufacturing Companies

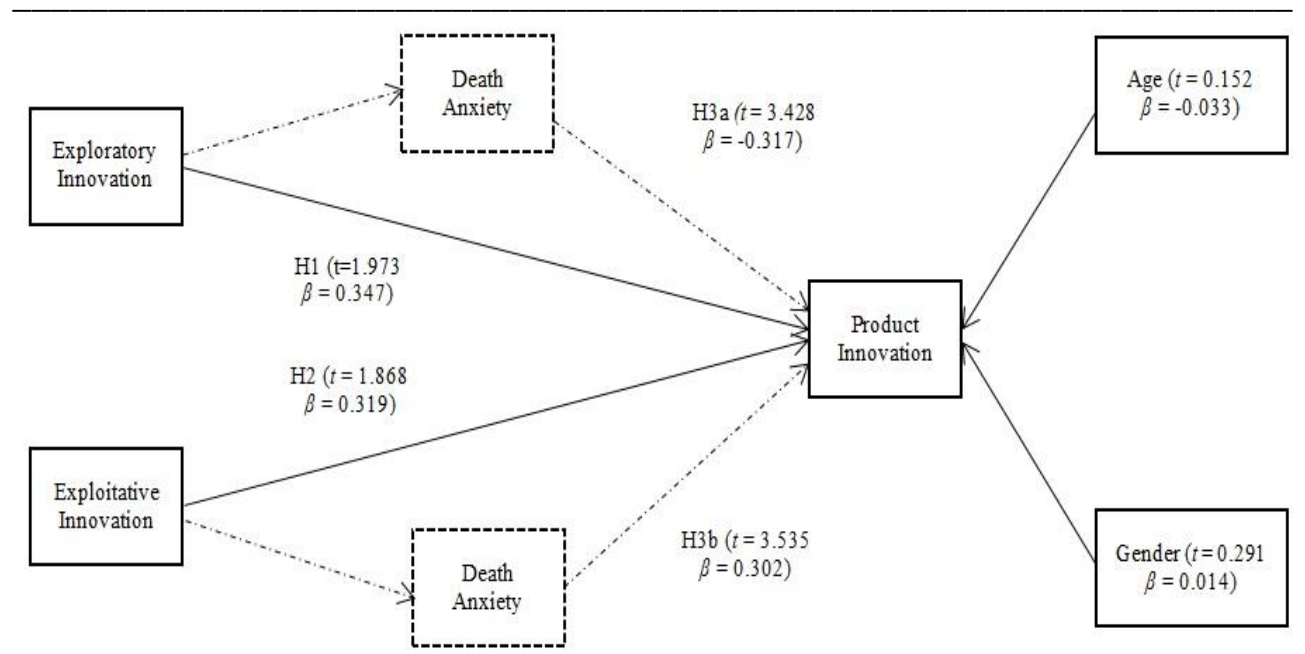

Figure 2. Final model and hypothesis testing results

\section{Empirical findings}

To determine the extent and impact of constructs, the path coefficients are analyzed (Table 3).

Table 3. Partial least squares path model results

\begin{tabular}{|l|c|c|}
\hline Relationship & $t$-value & $\begin{array}{l}\text { Path } \\
\text { coefficient }(\beta)\end{array}$ \\
\hline AGE $\rightarrow$ PI & 0.152 & -0.033 \\
\hline GENDER $\rightarrow$ PI & 0.291 & 0.014 \\
\hline EXPLOR $\rightarrow$ PI & $1.973^{*}$ & 0.347 \\
\hline EXPLOIT $\rightarrow$ PI & $1.868^{*}$ & 0.311 \\
\hline EXPLOR $\rightarrow$ DA & $3.428^{* * *}$ & -0.314 \\
\hline EXPLOIT $\rightarrow$ DA & $3.535^{* * *}$ & 0.302 \\
\hline \multicolumn{2}{|c|}{$* 0.05 ; * * p<0.01 ; * * *<0.001$}
\end{tabular}

A direct positive impact of EXPLOR and EXPLOIT on PI was found, confirming $\mathrm{H} 1$ and $\mathrm{H} 2$ hypothesis. EXPLOR is positively correlated with PI ( $\mathrm{t}$ value $=1.973, \beta=0.344, p<0.05$ ). In a similar vein, EXPLOIT is positively correlated with PI (t-value $=1.868, \beta=0.311, \mathrm{p}<0.05)$.

The path coefficient for EXPLOR-DA shows that DA is having an inhibiting effect on EXPLOR effects on PI ( $\mathrm{t}$-value $=3.428, \beta=-0.314, \mathrm{p}<0.001$ ). Therefore, H3a is not confirmed.

On the other hand, EXPLOIT -DA path coefficient shows that DA partially mediates the impact of EXPLOIT on PI ( $\mathrm{t}$-value $=3.535, \beta=0.302, \mathrm{p}<0.001$ ). Therefore, $\mathrm{H} 3 \mathrm{~b}$ is confirmed.

DOI: 10.24818/18423264/55.1.21.09 
Sebastian Ion Ceptureanu, Roy Cerqueti, Eduard Gabriel Ceptureanu, Gurjeet Dhesi, Iuliana Luchian

The mediation effects of DA are assessed by the variance accounted (VA). The VA (\%) for EXPLOIT is close to 50 percent $(49.26 \%)$ while for EXPLOR $(47.50 \%)$, suggesting partial mediation (Table 4$)$.

Table 4. Mediating effect of DA

\begin{tabular}{|c|c|c|c|c|}
\hline & \multicolumn{4}{|c|}{ DA } \\
\cline { 2 - 5 } & $\begin{array}{c}\text { Direct } \\
\text { Effect }\end{array}$ & $\begin{array}{c}\text { Indirect } \\
\text { Effect }\end{array}$ & $\begin{array}{c}\text { Total } \\
\text { Effect }\end{array}$ & $\begin{array}{c}\text { VA } \\
(\mathbf{\%})\end{array}$ \\
\hline EXPLOR $\rightarrow$ PI & 0.347 & -0.314 & 0.033 & $47.50 \%$ \\
\hline EXPLOIT $\rightarrow$ PI & 0.311 & 0.302 & 0.613 & $49.26 \%$ \\
\hline
\end{tabular}

Note: For EXPLOR, all effects were considered regardless of the sign (+ or -).

To evaluate the structural model, R2 (for the structural model's goodness of fit) and Q2 (for goodness of fit and the predictive power of the structural model) were used (Table 5).

Table 5. Structural model criteri
\begin{tabular}{|c|c|c|}
\hline Constructs & $\mathbf{R}^{\mathbf{2}}$ & $\mathbf{Q}^{\mathbf{2}}$ \\
\hline EXPLOR & - & - \\
\hline EXPLOIT & - & - \\
\hline DA & 0.807 & 0.729 \\
\hline PI & 0.822 & 0.735 \\
\hline Mean & 0.814 & 0.728 \\
\hline
\end{tabular}

\section{Concluding remarks and policy implications}

The purpose of this study was to demonstrate the effects of EXPLOR and EXPLOIT on PI, and to analyze the mediating effects of DA on these relationships.

In order to improve PI, entrepreneurs need to build the corresponding capabilities for both EXPLOR and EXPLOIT in their companies. Previously, scholars argue that EXPLOR and EXPLOIT are positively correlated with PI by accelerating the development of new products and improving the flexibility of existing products (Lin et al., 2017). The study founds evidence supporting these claims.

EXPLOR is usually chosen by those entrepreneurs focusing on disruptive innovation (Lin et al., 2017), favoring new, innovative product adoption. However, exclusive focus of EXPLOR may damage the existing products portfolio (Piao \& Zajac, 2016) and is a lengthy process, making the associated risks and costs also high.

Choice to develop the existing product range, the more conservative approach, makes the entrepreneurs favorable to EXPLOIT (Lin et al., 2017), since it enhances company's specific competences (Prange \& Verdier, 2011). The study demonstrates that the entrepreneurs are more prone to choose EXPLOIT rather 
Does Death Anxiety Inhibit Product Innovation? An Exploratory Study in Small Manufacturing Companies

than EXPLOR, seeking success in the short term by capitalizing the existing products, with the development of new, innovative products, is hampered by DA.

The study finds empirical evidence proving that the entrepreneurs' fear of death - captured by DA, in this study - partially mediates, positively and negatively, EXPLOR and EXPLOIT influence on PI. The findings show that DA is negatively affecting EXPLOR, with negative effects for radical innovation, and positively influencing EXPLOIT, supporting incremental innovation. The effects may be far reaching, only if considering the current SARS-COV-2 epidemics, which may radically change not only the social landscape, but also the way the entrepreneurs are substantiating their decisions.

Second, the present research shows that PI can be hampered by DA. DA activates a defensive behavior of entrepreneurs that acts, acting as a barrier to innovative products adoption. Responding to DA stimulus, entrepreneurs become innovation defensive, which is beneficial for EXPLOIT but detrimental for EXPLOR.

The negative effect of DA on PI provides more evidence of the impact of DA on entrepreneurs' response to innovation and how it affects the decisionmaking toward innovation.

The findings suggest that DA activates psychological self-protection mechanisms in entrepreneurs, making elements associated with newness and innovation products, such as risks and uncertainties, more important in their decision-making processes. These mechanisms transform, in fact, in passive innovation resistance (Heidenreich \& Handrich, 2015), many times unconscious, favoring the status quo instead of change (Heidenreich et al., 2016). This finding extends research on innovation by identifying a potential inhibitor of EXPLOR choice, an effect of existential threats perceived by entrepreneurs.

The last decade terrorist attacks (such as ISIS highly televised beheadings and terror attacks worldwide), pandemic diseases (with the SARS-COV-2 only the last of a string of global or regional diseases outbreaks), and the economic crises, dramatic increase in immigration in certain regions, such as the massive inflow of immigrants in European Union from North Africa or Middle East, often activate self-protective mechanism associated with DA in entrepreneurs.

Finally, the activation of DA may explain the high failure rates of new products (Heidenreich \& Kraemer, 2016). This study suggests that PI is affected by psychological factors because DA threatens entrepreneurs' sense of life meaning, inhibiting innovative products adoption.

The study presents several limitations. First, literature suggests that reminders of death exert short-term effects on existential threats (Lykins et al., 2007), the core of DA. This was the reason why the authors have chosen three-year duration for the survey. When entrepreneurs experience DA for longer durations, they may suffer more important and subtle psychological changes, as stated in post-traumatic growth theory (Tedeschi \& Calhoun, 2004). Still, there is not clear

DOI: $10.24818 / 18423264 / 55.1 .21 .09$ 
Sebastian Ion Ceptureanu, Roy Cerqueti, Eduard Gabriel Ceptureanu, Gurjeet Dhesi, Iuliana Luchian

what longer period of time means, since the psychological behavior of individuals may change abruptly or slowly depending on the nature of events.

Second, the focus of the study was restricted to new or improved innovative products in manufacturing small firms. A more granulated view of PI, including different classification of new products and different industries, may extend the understanding of how DA affects PI.

\section{REFERENCES}

[1]Birkinshaw, J., Gupta, K. (2013), Clarifying the Distinctive Contribution of Innovation Ambidexterity to the Field of Organization Studies. Academy of Management Perspectives 27(4), 287-298;

[2]Boeuf, B. (2019), The Impact of Death Anxiety on Attitude toward Product Innovation. Journal of Business Research 104, 44-60;

[3]Cai, W., Tang, Y-I., Wu, S., Li, H. (2017), Scale of Death Anxiety (SDA): Development and Validation. Frontiers in Psychology 8, 858;

[4]Cao, Q., Gedajlovic, E., Zhang, H. (2009), Unpacking Organizational Innovation Ambidexterity: Dimensions, Contingencies, and Synergistic Effects. Organization Science, 20(4), 781-796;

[5]Chuin, C.L., Choo, Y.C. (2009), Age, Gender, and Religiosity as Related to Death Anxiety. Sunway Academic Journal, 6, 1-16;

[6]Das, E., Duiven, R., Arendsen, J., Vermeulen, I. (2014), Exploring Killer Ads: A Terror Management Account of Death in Advertisements. Psychology \& Marketing, 31(10), 828-842;

[7]Diamantopoulos, A., Winklhofer, H.M. (2001), Index Construction with Formative Indicators: An Alternative to Scale Development. Journal of Marketing Research, 38, 269-277;

[8]Hair, J.F., Black, W.C., Babin, B.J., Anderson, R.E., Tatham, R.L. (2006), Multivariate Data Analysis. Upper Saddle River, N.J.: Pearson Prentice Hall; [9]He, Z.-L., Wong, P.-K. (2004), Exploration vs. Exploitation: An Empirical Test of the Innovation Ambidexterity Hypothesis. Organization Science, 15(4), 481-494;

[10]Heidenreich, S., Handrich, M. (2015), What about Passive Innovation Resistance? Investigating Adoption-Related Behavior from a Resistance Perspective. Journal of Product Innovation Management, 32(6), 878-903; [11]Heidenreich, S., Kraemer, T. (2016), Innovations - Doomed to Fail? Investigating Strategies to Overcome Passive Innovation Resistance. Journal of Product Innovation Management, 33(3), 277-297;

[12]Heidenreich, S., Kraemer, T., Handrich, M. (2016), Satisfied and Unwilling: Exploring Cognitive and Situational Resistance to Innovations. Journal of Business Research, 69(7), 2440-2447; 
Does Death Anxiety Inhibit Product Innovation? An Exploratory Study in Small Manufacturing Companies

[13]Jong, J., Halberstadt, J. (2019), Death Anxiety and Religious Belief: Responses to Commentaries. Religion, Brain and Behavior, 9(2), 207-2018; [14]Kim, S.H., Park, H.J. (2011), Effects of Social Influence on Consumers' Voluntary Adoption of Innovations Prompted by Others. Journal of Business Research, 64(11), 1190-1194;

[15]Lee, K., Woo, H.-G., Joshi, K. (2017), Pro-innovation Culture, Innovation Ambidexterity and New Product Development Performance: Polynomial

Regression and Response Surface Analysis. European Management Journal, 35, 249-260;

[16]Lin, H.E., McDonough, E.F., Yang, J., Wang, C. (2017), Aligning

Knowledge Assets for Exploitation, Exploration, and Innovation Ambidexterity:

A Study of Companies in High-Tech Parks in China. Journal of Product Innovation Management, 34(2), 122-140;

[17]Lykins, E.L., Segerstrom, S.C., Averill, A.J., Evans, D.R., Kemeny, M.E. (2007), Goal Shifts Following Reminders of Mortality: Reconciling

Posttraumatic Growth and Terror Management Theory. Personality and Social Psychology Bulletin, 33(8), 1088-1099;

[18]Mason, C., Perreault Jr., W.D. (1991), Collinearity, Power, and Interpretation of Multiple Regression Analysis. Journal of Marketing Research, 28, 268-280;

[19]Markovic, S., Jovanovic, M., Bagherzadeh, M., Sancha, C., Sarafinovska, M., Qiu, Y. (2020), Priorities when Selecting Business Partners for Service Innovation: The Contingency Role of Product Innovation. Industrial Marketing Management, 88, 378-388;

[20]Moon, S., Bergey, P.K., Bove, L.L., Robinson, S. (2016), Message Framing and Individual Traits in Adopting Innovative, Sustainable Products (Isps): Evidence from Biofuel Adoption. Journal of Business Research, 69(9), 35533560 ;

[21]Piao, M., Zajac, E.J. (2016), How Exploitation Impedes and Impels

Exploration: Theory and Evidence. Strategic Management Journal, 37(7), 14311447 ;

[22]Prange, C., Verdier, S. (2011), Dynamic Capabilities, Internationalization Processes and Performance. Journal of World Business, 46(1), 126-133;

[23]Rothaermel, F.T., Alexandre, M.T. (2009), Innovation Ambidexterity in Technology Sourcing: The Moderating Role of Absorptive Capacity.

Organization Science, 20(4), 759-780;

[24]Routledge, C., Arndt, J., Wildschut, T., Sedikides, C., Hart, C.M., Juhl, J., Vingerhoets, J.J.M., Schlotz, W. (2011), The Past Makes the Present Meaningful: Nostalgia as an Existential Resource. Journal of Personality and Social Psychology, 101(3), 638-652;

[25]Sedikides, C., Wildschut, T. (2018), Finding Meaning in Nostalgia. Review of General Psychology, 22(1), 48-61;

DOI: 10.24818/18423264/55.1.21.09 
Sebastian Ion Ceptureanu, Roy Cerqueti, Eduard Gabriel Ceptureanu, Gurjeet Dhesi, Iuliana Luchian

[26]Talke, K., Heidenreich, S. (2014), How to Overcome Pro-change Bias: Incorporating Passive and Active Innovation Resistance in Innovation Decision Models. Journal of Product Innovation Management, 31(5), 894-907;

[27]Tedeschi, R.G., Calhoun, L.G. (2004), Post-traumatic Growth: Conceptual Foundations and Empirical Evidence. Psychological Inquiry, 15(1), 1-18; [28]Wang, C.L. Ahmed, P.K. (2004), The Development and Validation of the Organizational Innovativeness Construct Using Confirmatory Factor Analysis. European Journal of Innovation Management, 7(4), 303-313;

[29]Wei, Z.L., Zhao, J., Zhang, C.L. (2014), Organizational Innovation Ambidexterity, Market Orientation, and Firm Performance. Journal of Engineering and Technology Management, 33, 134-153;

[30]Zhang, Y., Li, H.Y. (2010), Innovation Search of New Ventures in a Technology Cluster: The Role of Ties with Service Intermediaries. Strategic Management Journal, 31, 88-109;

[31]Zhao, M., Hoeffler, S., Dahl, D.W. (2012), Imagination Difficulty and New Product Evaluation. Journal of Product Innovation Management, 29(S1), 76-90. 